\title{
Determination of the relationship between respiratory function and respiratory muscle strength
} and grip strength of elite athletes

\author{
Tuğba KOCAHAN ${ }^{1}$, Bihter AKINOĞLU², Oğuzhan METE², Adnan HASANOĞLU1
}

${ }^{1}$ The Ministry of Youth and Sports, Sports General Directorship, Department of Health Services, Center of Athlete Training and Health Research, Ankara, Turkey.

${ }^{2}$ Department of Physiotherapy and Rehabilitation, Faculty of Health Sciences, Ankara Yıldırım Beyazıt University, Ankara, Turkey.

\section{SUMMARY}

Functional, physical, and physiological characteristics of the athletes are the factors that affect the sports performance. Grip strength, respiratory function, and respiratory muscle strength have an effect on the sports performance of the athletes. This study aimed to determine the relationship between respiratory function and respiratory muscle strength and grip strength, which are effective in sports performance of the athletes.

This study included 61 elite national team athletes (age: $20.63 \pm 3.08$ years; height: $172.26 \pm 8.84$ cm; body weight: 71.65 $\pm 14.28 \mathrm{~kg}$; body mass index: $23.82 \pm 3.33 \mathrm{~kg} / \mathrm{m} 2 ;$ sport age: $8.61 \pm 4.34$ years). Respiratory function and respiratory muscle strength were assessed using a digital spirometer, and hand strength was assessed by a hand dynamometer. The relationship between respiratory function and respiratory muscle strength and grip strength of the athletes was analyzed using Pearson correlation coefficient.

At the end of the study, it was found that forced vital capacity, 1-s forced expiratory volume (FEVI), peak expiratory flow (PEF), maximum voluntary ventilation (MVV), maximal inspiratory pressure (MIP), and maximal expiratory pressure (MEP) values were associated with grip strength (r: $0.302 / 0.678, P<0.05)$.

In elite athletes, respiratory function and respiratory muscle strength were found to be related to grip strength. In the light of these results, it can be interpreted that the muscle strength of athletes develops parallel to respiratory muscle strength and respiratory function. Therefore, it is believed that exercises for increasing respiratory function and respiratory muscle strengths should be included in athletes' training programs to increase muscle strength, which is important in sports performance of athletes.

Key words: Athlete, grip strength, muscle strength, respiratory muscle strength, respiratory function test.

\section{INTRODUCTION}

The relationship between physical properties, physical capacity, and performance has been a source of interest for researchers. One of the main goals of the sport sciences is to increase the efficiency of the athletes and anticipate the development of athletes. The functional, physical, and physiological characteristics of the athletes are the factors that influence the sports performance. Hence, it is necessary to investigate the functional, physical, and physiological properties of the athletes (1-3).

Respiratory function, respiratory muscle strength, and grip strength are factors affecting sportive performances of athletes. The relationship between sport-specific performance and respiratory function, respiratory muscle strength, and grip strength is clearly shown in the literature $(3,4)$. 
Studies in the literature indicate that the grip strength of athletes has a significant influence on the performance of the athletes in different sports branches. $(1,2,4-6)$. Also, several studies have examined the relationship between respiratory function and respiratory muscle strength in relation to sportive performance (7-9). However, studies in the literature investigating the relationship between respiratory function and respiratory muscle strength and grip strength were performed in healthy populations, geriatric individuals, and patients with systemic diseases (10-14). Studies investigating the relationship of these parameters affecting sports performance are limited in athletes. Therefore, the aim of this study was to examine the relationship between respiratory function and respiratory muscle strength and grip strength, which are effective in sports performance of the athletes.

\section{MATERIALS AND METHODS}

Study design and participants

The elite judo, shovel, gymnastics, Greco-Roman wrestling, and speedboat athletes from the Turkey Olympic Preparatory Center were included in the study. The inclusion criteria for the study were individuals aged more than 18 years, individuals involved in professional sport for at least 3 years, individuals having no orthopedic injuries that would affect grip strength in the last 6 months, individuals with no acute or chronic respiratory infection, individuals having cognitive state required for the assessment, and individuals who volunteered to participate in the study. The study began with 70 athletes. The study was completed with 61 athletes (age: $20.63 \pm 3.08$ years; height: $172.26 \pm 8.84 \mathrm{~cm}$; body weight: $71.65 \pm 14.28 \mathrm{~kg}$; body mass index: $23.82 \pm 3.33 \mathrm{~kg} / \mathrm{m}^{2}$; sport age: $8.61 \pm 4.34$ years) (Table 1) because 9 athletes did not meet the inclusion criteria. Further, 41 of the athletes participating in the study were males athletes and 20 were females. Also, 51 of the athletes were right dominant and 10 left dominant. Dominant status was determined by asking the athletes. Moreover, 21 of the athletes were judo, 16 shovels, 13 gymnastics, 7 Greco-Roman wrestlers, and 4 fast-paced athletes (Table 2).
TABLE 1: Demographic characteristics of the athletes.

\begin{tabular}{lll}
\hline & $\mathrm{X} \pm \mathrm{SD}$ & Min-Max \\
\hline Age (year) & $20.63 \pm 3.08$ & $18-32$ \\
Length $(\mathrm{cm})$ & $172.26 \pm 8.84$ & $153-192$ \\
Body weight $(\mathrm{kg})$ & $71.65 \pm 14.28$ & $46-138$ \\
BMI $\left(\mathrm{kg} / \mathrm{m}^{2}\right)$ & $23.82 \pm 3.33$ & $18.82-41.21$ \\
Sport age (year) & $8.61 \pm 4.34$ & $3-20$ \\
\hline BMI, Body mass index. & & \\
\hline
\end{tabular}

TABLE 2: Demographic characteristics of the athletes.

\begin{tabular}{llll}
\hline \multirow{2}{*}{ Gender } & Male & N & $\%$ \\
\hline \multirow{2}{*}{ Dominant side } & Female & 41 & 67.2 \\
& Right & 20 & 32.8 \\
\hline \multirow{2}{*}{ Sports branch } & Left & 51 & 83.6 \\
& Judo & 10 & 16.4 \\
& Shovel & 21 & 34.4 \\
& Gymnastics & 16 & 26.2 \\
& Greco-Roman wrestling & 7 & 11.5 \\
& Speedboat & 4 & 6.6
\end{tabular}

\section{Evaluations}

\section{Evaluation of respiratory function and respiratory muscle strength}

The respiratory function and respiratory muscle strength of the athletes were measured using the portable digital spirometer (Pony FX Cosmed) and the American Thoracic Society (ATS)/ European Respiratory Society (ERS) acceptability criteria. The measurements were made in the same environment and by the same evaluator. Prior to the measurements, all participants were informed about the test, and the participants' height, weight, date of birth, sex, race information were recorded on the spirometer device. Before the test was started, several applications were made for participants to adapt to the device and determine whether the test was understood correctly. The tests were carried out in a 
comfortable seat on an armchair. During the tests, the athlete's nose was covered with the nose clip. To not miss out the air, the athletes wanted to close the mouthpiece of the spirometry with their lips without covering the mouth of the spirometry with the tongue and teeth. Each test was repeated three times, and the best result was used for statistical analysis.

For the forced vital capacity (FVC) maneuver, the athletes were first asked to make a strong and deep inspiration. At the end of the inspiration, the athletes were asked to perform rapid explosive and strong expiration and wanted to breathe deeply again when all the air in their lungs was gone. The FVC, forced expiratory volume (FEV1), and peak expiratory flow (PEF) values obtained as a result of the test were recorded.

For maximum voluntary ventilation (MVV), the athletes were asked to take a fast, deep, and rhythmic breath for 12s. During the test, verbal statements were made by the evaluator to allow the athletes to adjust the respiratory rhythm (15).

Measurements of respiratory muscle strength were assessed using maximal inspiratory pressure (MIP) and maximal expiratory pressure (MEP) tests, which were simple and noninvasive methods. For the MIP test, the athlete was asked to expel the air from their lungs first and then make a deep, fast and strong inspiration for at least $1 \mathrm{~s}$ against resistance. For the MEP test, the athlete was asked to inspire air in his lungs first and then make a deep, fast, and strong expiration for at least $1 \mathrm{~s}$ against resistance. The MIP and MEP values obtained from the tests were recorded (16-18).

\section{Evaluation of grip strength}

The grip strength of the athletes was assessed using Takei GRIP-D (Japanese) brand hand dynamometer. Since the methods of measuring the grip strength vary in the literature, three different measurement methods were applied (19). For the first measurement, the athlete was asked to squeeze the hand dynamometer while standing, with the shoulder slightly abducted, the elbow 90 degrees flexed, and the forearm in the neutral position. For the second measurement, the athlete was asked to squeeze the hand dynamometer while standing, with the shoulder slightly abducted, with the elbow fully extended, and with the forearm in the neutral position (20). For the third measurement, the athlete was asked to squeeze the hand dynamometer in sitting position with the shoulder in adduction, elbow in $90^{\circ}$ flexion, and forearm in a neutral position $(19,21)$. For each measurement method, the test was repeated three times on both dominant and nondominant sides, and the average value of three repetitions was recorded in kilograms $(\mathrm{kg})(21)$.

\section{Statistical analysis}

The data collected on the respiratory function, and respiratory muscle strength and grip strength of the athletes were analyzed using Statistical Package for Social Sciences Inc. (IL, USA) for Windows Release 22.0 statistical package program. Visual (histogram, probability plots) and analytical method (Kolmogorov-Smirnov test) were used to identify whether the variables were normally distributed. All the numerical data used for evaluating FVC, FEV1, PEF, MIP, MEP, and grip strength were observed to have a normal distribution. Therefore, the relationship between the variables was analyzed using the Pearson correlation coefficient. Statistical error level was determined as $P<0.05$.

\section{RESULTS}

The descriptive statistics of the data obtained as a result of evaluations of respiratory function, respiratory muscle strength, and grip strength of the athletes are shown in Table 3.

When the relationship between the FVC, FEV1, PEF, MVV, MIP, MEP. and grip strengths of the athletes were examined as a result of the study, all the analyzed parameters were seen to be related to each other (r: 0.302/0.678; $P<0.05)$.

The athletes' FVC values were found to be strongly positively correlated with the grip strength parameters, the PEF values were moderately positively correlated with the grip strength parameters, MVV values were moderately positively correlated with grip strength parameters, MIP values were moderately positively correlated with the grip strength parameters, and 
TABLE 3: Descriptive statistics of respiratory function, respiratory muscle strength, and grip strength of athletes.

\begin{tabular}{|c|c|c|c|}
\hline Grip strength (kg) & & $X \pm S D$ & Min-Max \\
\hline \multirow[t]{2}{*}{ First position: Standing, elbow extended } & Dominant side & $44.25 \pm 10.61$ & $22.50-62.23$ \\
\hline & Nondominant side & $42.86 \pm 10.62$ & $20.03-60.53$ \\
\hline \multirow[t]{2}{*}{ Second position: Standing, elbow $90^{\circ}$ Flexed } & Dominant side & $41.54 \pm 10.16$ & $21.17-58.16$ \\
\hline & Nondominant side & $41.58 \pm 10.29$ & $21.10-59.30$ \\
\hline \multirow[t]{2}{*}{ Third position: Sitting, elbow $90^{\circ}$ Flexed } & Dominant side & $40.71 \pm 10.1$ & $20.83-63.87$ \\
\hline & Nondominant side & $39.86 \pm 10.01$ & 21. $23-59.13$ \\
\hline FVC (L) & $4.93 \pm 0.99$ & $3.31-7.82$ & \\
\hline FEV1 (L) & $4.17 \pm 0.82$ & $2.57-6.03$ & \\
\hline PEF (L/S) & $8.03 \pm 2.07$ & $3.96-13.28$ & \\
\hline MVV (L/min) & $159.96 \pm 38.59$ & $77.80-254.40$ & \\
\hline $\mathrm{MIP}\left(\mathrm{cmH}_{2} \mathrm{O}\right)$ & $126.09 \pm 25.87$ & 69-184 & \\
\hline $\operatorname{MEP}\left(\mathrm{cmH}_{2} \mathrm{O}\right)$ & $148.81 \pm 35.84$ & $82-241$ & \\
\hline
\end{tabular}

FVC: Forced vital capacity; FEV1: First forced expiratory volume; PEF: Peak flow; MVV: Maximum voluntary ventilation; MIP: Maximum inspiratory pressure; MEP: Maximum expiratory pressure.

MEP values were low-to-moderate correlated with grip strength position with the elbow extended. In this position, FEV1 values parameters. FEV1 values were moderately positively correlated were strongly positive correlated with the dominant side grip with all grip strength parameters except grip strength in standing strength (Table 4).

TABLE 4: Relationship between FVC, FEV1, PEF, MIP, MEP, and grip strength of athletes.

\begin{tabular}{|c|c|c|c|c|c|c|c|c|c|c|c|c|}
\hline & \multicolumn{4}{|c|}{$\begin{array}{l}\text { Standing, elbow extended } \\
\text { Grip strength }(\mathrm{kg})\end{array}$} & \multicolumn{4}{|c|}{$\begin{array}{c}\text { Standing, elbow } 90^{\circ} \text { flexed } \\
\text { Grip strength }(\mathrm{kg})\end{array}$} & \multicolumn{4}{|c|}{$\begin{array}{l}\text { Sitting, elbow } 90^{\circ} \text { flexed } \\
\text { Grip strength }(\mathrm{kg})\end{array}$} \\
\hline & \multicolumn{2}{|c|}{$\begin{array}{l}\text { Dominant } \\
\text { side }\end{array}$} & \multicolumn{2}{|c|}{$\begin{array}{l}\text { Nondominant } \\
\text { side }\end{array}$} & \multicolumn{2}{|c|}{ Dominant side } & \multicolumn{2}{|c|}{$\begin{array}{l}\text { Nondominant } \\
\text { side }\end{array}$} & \multicolumn{2}{|c|}{$\begin{array}{l}\text { Dominant } \\
\text { side }\end{array}$} & \multicolumn{2}{|c|}{$\begin{array}{l}\text { Nondominant } \\
\text { side }\end{array}$} \\
\hline & $\mathrm{P}$ & $r$ & $P$ & $r$ & $\mathrm{P}$ & 1 & $P$ & $r$ & $P$ & $r$ & $\mathrm{P}$ & $r$ \\
\hline FVC (L) & $<0.001$ & 0.678 & $<0.001$ & 0.610 & $<0.001$ & 0.622 & $<0.001$ & 0.617 & $<0.001$ & 0.654 & $<0.001$ & 0.642 \\
\hline FEV1 (L) & $<0.001$ & 0,605 & $<0.001$ & 0.532 & $<0.001$ & 0.534 & $<0.001$ & 0.542 & $<0.001$ & 0.588 & $<0.001$ & 0.565 \\
\hline PEF (L/s) & $<0.001$ & 0.569 & $<0.001$ & 0.524 & $<0.001$ & 0.524 & $<0 . .001$ & 0.544 & $<0.001$ & 0.596 & $<0.001$ & 0.591 \\
\hline MVV (L/min) & $<0.001$ & 0.514 & $<0.001$ & 0.473 & $<0.001$ & 0.490 & $<0.001$ & 0.495 & $<0.001$ & 0.539 & $<0.001$ & 0.526 \\
\hline $\operatorname{MIP}\left(\mathrm{cmH}_{2} \mathrm{O}\right)$ & 0.001 & 0.408 & $<0.001$ & 0.471 & 0.001 & 0.428 & $<0.001$ & 0.475 & $<0.001$ & 0.494 & $<0.001$ & 0.498 \\
\hline $\operatorname{MEP}\left(\mathrm{cmH}_{2} \mathrm{O}\right)$ & 0.013 & 0.316 & 0.018 & 0.302 & 0.012 & 0.321 & 0.015 & 0.310 & 0.006 & 0.345 & 0.003 & 0.378 \\
\hline
\end{tabular}




\section{DISCUSSION}

The study showed that the grip strength of the athletes was correlated with the respiratory muscle strength and respiratory function. This novel study included different sports branches and investigated the relationship between grip strength and respiratory function and respiratory muscle strength, which affected sports performances of athletes.

Grip strength is related to general physical function, muscle mass, and health status (22). Also, both peripheral muscle strength and general muscle strength are correlated with grip strength $(23,24)$. Therefore, grip strength can be used as a tool for predicting general muscle strength (23). In the present study, grip strength measurement was used, which was easy to apply and demonstrated efficacy on muscle strength measurement in the literature to evaluate the muscle strength of athletes.

Some studies in the literature determined the relationship between grip strength and performance in the athletes. Ferragut et al showed that grip strength in elite water ball athletes was a significant factor in the performance of athletes and that maximal grip strength was related to the throwing speed of the athletes (4). Gonçalves et al showed that maximal grip strength in judo athletes was related to the judo fitness test, which was specific to judo performance (5). Zampagni et al found that grip strength was related to swimming performance and that grip strength was effective in predicting short-distance swimming performance in elite master swimming (6). Geladas et al emphasized that grip strength was an important factor in predicting 100-m freestyle swimming performance in young male swimmers (1). lermakov et al showed that the grip strength of martial arts athletes had a significant influence on the athletes' sportive achievements (2).

Similarly, a relationship exists between respiratory functions and respiratory muscle strength and sports performance. In this context, Noriega-Sanchez et al performed a study on young swimming athletes and showed that the 100-m swimming test was related to forced inspiratory volume in first second (FIV1) and FVC in female athletes and FIV1 in male athletes. It was also emphasized that only FIV1 of athletes among the evaluated anthropometric, conditioning, and physiological parameters in the study was a predictor of 100-m swimming performance. (7). Salinero et al performed a study on marathon runners and demonstrated that the duration of the race was related to the FVC, FEV1, and PEF values and the high pulmonary capacity could be a critical variable for the marathon performance of amateur runners (8). Volianitis et al conducted a study on shovel athletes and showed that the performance of shovel athletes improved as a result of inspiratory muscle training (9).

The relationship between grip strength and respiratory function and respiratory muscle strength has been demonstrated in studies conducted on different populations. Sillanpää et al investigated the relationship between muscle strength and pulmonary function in healthy elderly people and demonstrated that the FVC, FEV1, and FEF50 values increased as the grip strength increased (10). Enright et al showed that grip strength and MIP values were interrelated in the geriatric population (11). Dias et al showed that PEF in geriatric individuals was associated with grip strength in women (12). Bae et al showed that the grip strength in children and adolescents was associated with FEV1 and FVC. They also indicated that muscle strengthening exercises, in addition to aerobic exercise, were necessary for the development of pulmonary function (13). Sahin et al emphasized that MIP and MEP values were related to grip strength and that grip strength might be a determinant of respiratory muscle strength in patients with fibromyalgia syndrome. The findings indicated that the decrease in the strength of the respiratory muscles might contribute to the decrease in peripheral muscle strength (14). The studies in the literature related to respiratory function and respiratory muscle strength and peripheral muscle strength were the ones showing a decrease in pulmonary capacity mostly associated with age and the negative effects of physiological changes in pulmonary and pulmonary functions due to chronic lung diseases on peripheral muscle strength (10, 25). In the present study, it was hypothesized that the peripheral muscle strength increased with the athletes' lung volumes and 
respiratory muscle strength. Indeed, the results supported the aforementioned hypothesis.

The present study showed that elite athletes' respiratory function and respiratory muscle strength were associated with grip strength, which is a general indicator of muscle strength. This relationship could be interpreted as the development of lung functions and respiratory muscle strength to provide necessary oxygenation to allow the muscles to release force. Therefore, when the relationship between sports performance and strength of peripheral muscles of athletes is taken into account, it is presumed that training and exercises for increasing respiratory function and respiratory muscle strength should be included in the routine training programs to increase muscle strength, which is important in the sportive performance of athletes.

\section{REFERENCES}

1. Geladas ND, Nassis GP, Pavlicevic S. Somatic and physical traits affecting sprint swimming performance in young swimmers. Int J Sport Med. 2005; 26(02):139-144.

2. Iermakov S, Podrigalo LV, Jagiełło W. Hand-grip strength as an indicator for predicting the success in martial arts athletes. Archives of Budo, 2016;12: 179-186.

3. Birinci MC, Yılmaz AK, Erkin A, Şahbaz S, Aydın İ. Determination of relationship between respiratory parameters and aerobic capacity of referees. Procedia Soc Behav Sci. 2014:152;12671273.

4. Ferragut $C$, Vila $H$, Abraldes JA, Argudo F, Rodriguez N, Alcaraz PE. Relationship among maximal grip, throwing velocity and anthropometric parameters in elite water polo players. J Sports Med Phys Fit. 2011;51(1): 26.

5. Moraes Gonçalves $M$, Borba-Pinheiro CJ, Marson RA, Rodrigues Camposo L, dos Reis Saraiva A, da Silva Novaes J. Correlation between maximum isometric strength variables and specific performance of Brazilian military judokas. Motricidade, 2017;13(1):68-76.

6. Zampagni $M L$, Casino $D$, Benelli $P$, Visani $A$, Marcacci $M, D e$ Vito, G. Anthropometric and strength variables to predict freestyle performance times in elite master swimmers. J Strength Cond Res. 2008:22(4);1298-1307.

7. Noriega-Sánchez SA, Legaz-Arrese A, Suarez-Arrones $L$, Santalla A, Floría P, Munguía-Izquierdo D. Forced Inspiratory Volume in the First Second as Predictor of Front-Crawl Performance in Young Sprint Swimmers. J Strength Cond Res 2015:29(1);188-194.
8. Salinero JJ, Soriano ML, Ruiz-Vicente D, Gonzalez-Millan C, Areces F, Gallo-Salazar C, et al. Respiratory function is associated to marathon race time. J Sports Med Phys Fit. 2016:56(12);1433-1438.

9. Volianitis S, McConnell AK, Koutedakis Y, McNaughton LR, Backx K, \& Jones DA. Inspiratory muscle training improves rowing performance. Medicine \& Science in Sports \& Exercise, 2001: 33(5); 803-809.

10. Sillanpää E, Stenroth L, Bijlsma AY, Rantanen T, McPhee JS, Maden-Wilkinson TM, et al. Associations between muscle strength, spirometric pulmonary function and mobility in healthy older adults. Age, 2014:36(4), 9667.

11. Enright PL, Kronmal RA, Manolio TA, Schenker MB, Hyatt RE. Respiratory muscle strength in the elderly. Correlates and reference values. Cardiovascular Health Study Research Group. Am J Respir Crit Care Med. 1994:149(2), 430-438.

12. Sahin G, Ulubas B, Calikoglu M, Erdogan C. Handgrip strength, pulmonary function tests, and pulmonary muscle strength in fibromyalgia syndrome: is there any relationship?. South Med J. 2004:97(1), 25-30.

13. Bae JY, Jang KS, Kang S, Han DH, Yang W, Shin KO. Correlation between basic physical fitness and pulmonary function in Korean children and adolescents: a cross-sectional survey. J Phys Ther Sci, 2015:27(9), 2687-2692.

14. Ritti-Dias RM, Cucato GG, de Mello Franco FG, Cendoroglo MS, Nasri F, Monteiro-Costa ML, et al. Peak expiratory flow mediates the relationship between handgrip strength and timed up and go performance in elderly women, but not men. Clinics, 2016:71(9), 517-520.

15. Miller MR, Hankinson JATS, Brusasco V, Burgos F, Casaburi R, Coates $A$, et al. Standardisation of spirometry. Eur Respir J. 2005:26(2), 319-338.

16. European Respiratory Society, American Thoracic Society. ATS/ERS Statement on respiratory muscle testing. Am J Respir Crit Care Med, 2002:166(4), 518.

17. Evans JA, Whitelaw WA. The assessment of maximal respiratory mouth pressures in adults. Respir Care. 2009:54(10);1348-1359.

18. Dimitriadis Z, Kapreli E, Konstantinidou I, Oldham J, Strimpakos N. Test/retest reliability of maximum mouth pressure measurements with the MicroRPM in healthy volunteers. Respir Care. 2011:56(6);776-782.

19. Roberts HC, Denison HJ, Martin HJ, Patel HP, Syddall $\mathrm{H}$, Cooper, $\mathrm{C}$, et al. A review of the measurement of grip strength in clinical and epidemiological studies: towards a standardised approach. Age Ageing. 2011:40(4), 423-429.

20. España-Romero V, Ortega FB, Vicente-Rodríguez G, Artero EG, Rey JP, Ruiz JR. Elbow position affects handgrip strength in adolescents: validity and reliability of Jamar, DynEx, and TKK dynamometers. J Strength Cond Res. 2010;24(1), 272277. 
21. Mathiowetz V, Kashman N, Volland G, Weber K, Dowe M, Rogers S. Grip and pinch strength: normative data for adults. Arch Phys Med Rehabil, 1985:66(2), 69-74.

22. Bohannon RW. Muscle strength: clinical and prognostic value of hand-grip dynamometry. Curr Opin Clin Nutr Metab Care. 2015:18(5), 465-470.

23. Wind $A E$, Takken $T$, Helders $P J$, Engelbert $R H$. Is grip strength a predictor for total muscle strength in healthy children, adolescents, and young adults?. Eur J Pediatr. 2010:169(3);281-287
24. Mandalidis D, O'Brien M. Relationship between handgrip isometric strength and isokinetic moment data of the shoulder stabilisers. J Bodyw Mov Ther. 2010:14(1);19-26.

25. Maltais F, Decramer $M$, Casaburi $R$, Barreiro $E$, Burelle $Y$, Debigare R, et al. An official American Thoracic Society/ European Respiratory Society statement: update on limb muscle dysfunction in chronic obstructive pulmonary disease. Am J Respir Crit Care Med. 2014:189(9);15-62. 